\section{Autosomal dominant congenital superior oblique palsy}

\begin{abstract}
Purpose We describe a mother and all her offspring with congenital superior oblique palsy (CSOP), and a father and all his sons with unilateral CSOP. We discuss the inheritance pattern in our pedigrees and compare it with previous reports.

Method All available family members were examined. The prism cover test was performed. Ocular movements were examined in all positions of gaze and where possible a Hess chart plotted. Lang and TNO stereotests were used to determine the stereo-acuity. The results of these tests combined with the Bielschowsky head tilt test (BHTT) were used to confirm the diagnosis of superior oblique palsy. The condition was classified as

Method

A full orthoptic examination was carried out to establish a diagnosis. The following tests were performed where the age and co-operation of the patient allowed. The visual acuity was measured. The prism cover test was performed. Ocular movements were examined in all positions of gaze and where possible a Hess chart plotted. Lang and TNO stereotests were used to determine the stereo-acuity.

The results of these tests combined with the Bielschowsky head tilt test (BHTT) were used to confirm the diagnosis of superior oblique palsy. The condition was classified as congenital if it presented early based on history or the observation of old photographs, and in the absence of a causative factor.
\end{abstract} congenital if it presented early based on history or the observation of old photographs and in the absence of a causative factor. Results The affected members of family A consist of a father and his three sons with unilateral CSOP. His daughter had a mild weakness of her left inferior and superior rectus muscle. One of his sons was asymptomatic and only recognised on screening of the family for the study. The affected members of family $B$ consist of a mother and her younger daughter with unilateral CSOP and her older daughter with bilateral CSOP. She had no other children. Conclusions Our families demonstrate what is probably an autosomal dominant form of CSOP. It is possible that hereditary CSOP is more common than previously reported.

Key words Autosomal dominant, Congenital, Inheritance, Oblique, Palsy, Superior

Superior oblique palsy is the most common isolated extraocular muscle palsy seen by the strabismologist. ${ }^{1}$ There are very few reports depicting the inheritance pattern in congenital superior oblique palsy (CSOP). ${ }^{2-6}$

We describe two families with CSOP: a mother and her two daughters, and a father and his three sons. We discuss the inheritance pattern in our pedigrees and compare it with previous reports.

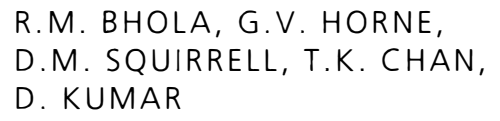

\section{Results}

\section{Family $A$}

Family A consists of a father and his three sons with unilateral CSOP. Table 1 shows the results of orthoptic investigation, Fig. 1 the Hess charts and Fig. 4 the family tree of all affected members of family A.

Three generations of this family are presented. The father (A II.3) was the first case of CSOP in this pedigree to present and he had three affected sons (A III.1, A III.2, A III.3). The 39-year-old son (A III.1) had experienced no ocular symptoms and his mild superior oblique palsy was only detected when the entire family was examined for the purpose of this study. The 37-year-old daughter (A III.4) did not show a specific ocular muscle underaction, but on left gaze demonstrated a left hypophoria on elevation and a left hyperphoria on depression. This was thought to be due to weakness of the left superior and inferior rectus muscle. The mother (father's wife) and the grandchildren were all examined and found to be normal.

\section{Family B}

Family B consists of a mother (B.II.2) and younger daughter (B III.2) with right CSOP, and older daughter (B III.1) with bilateral CSOP. Table 2 shows the orthoptic results, Fig. 2 the photographs, Fig. 3 the Hess charts and Fig. 4
R.M. Bhola

D.M. Squirrell

T.K. Chan

Department of

Ophthalmology

Royal Hallamshire Hospital Sheffield, UK

\section{G.V. Horne}

King Edward VII Hospital Windsor, UK

\section{Kumar}

North Trent Genetic Service Sheffield Children Hospital Sheffield, UK

Ronnie M. Bhola Department of Ophthalmology A Floor, Royal Hallamshire Hospital

Sheffield S10 2JF, UK

Tel: 07818414608

e-mail:

ronmb2@hotmail.com

Presented in part at the annual scientific conference of the British Orthoptic Society, July 2000

Received: 11 October 2000 Accepted in revised form: 14 February 2001 


\begin{tabular}{|c|c|c|c|c|c|}
\hline & $\begin{array}{l}\text { A II. } 3 \\
\text { father }\end{array}$ & $\begin{array}{l}\text { A III. } 1 \\
\text { son }\end{array}$ & $\begin{array}{l}\text { A III. } 2 \\
\text { son }\end{array}$ & $\begin{array}{l}\text { A III. } 3 \\
\text { son }\end{array}$ & $\begin{array}{l}\text { A III. } 4 \\
\text { daughter }\end{array}$ \\
\hline Age (years)/sex & $60 / \mathrm{M}$ & $39 / \mathrm{M}$ & $35 / \mathrm{M}$ & $40 / \mathrm{M}$ & $37 / F$ \\
\hline Time of onset & Childhood & Childhood & Childhood & Childhood & Childhood \\
\hline Visual acuity & $6 / 6 \quad 6 / 6$ & $6 / 6 \quad 6 / 6$ & $6 / 6 \quad 6 / 6$ & $6 / 6 \quad 6 / 6$ & $6 / 6 \quad 6 / 6$ \\
\hline Abnormal head posture & Yes & No & Yes & Yes & No \\
\hline Cover test in primary position & $\mathrm{R} / \mathrm{L} 2^{\Delta}$ & $\mathrm{L} / \mathrm{R} 1^{\Delta}$ & $\mathrm{L} / \mathrm{R} 11^{\Delta}$ & $\mathrm{L} / \mathrm{R} 5^{\Delta}$ & Exophoria \\
\hline Binocular single vision & Yes & Yes & Yes & Yes & Yes \\
\hline Superior oblique underaction & Right & Left & Left & Left & \\
\hline Inferior oblique overaction & Right & Left & Left & Left & \\
\hline Bielschowsky head tilt test & Equivocal & Positive & Positive & Positive & \\
\hline
\end{tabular}

the family tree of the affected members of family B. The younger daughter was the first case in this pedigree to present. The older daughter had a small V-pattern esophoria, underaction of the right and left superior obliques, and a right hypertropia on right head tilt and left hypertropia on left head tilt. She had bilateral superior oblique palsy.

\section{Discussion}

The aetiology of CSOP is still unknown. Many causes have been suggested including aplasia of the trochlear nucleus, nerve injury and anatomical abnormalities of the superior oblique tendon and/or muscle. ${ }^{7-10}$ The trochlear nerve is liable to damage as it emerges from the dorsal surface of the brain, ${ }^{8}$ and it has been suggested that trochlear nerve injury may occur during birth trauma. ${ }^{1}$ This nerve injury can result in retrograde nerve death rendering the trochlear nucleus aplastic, ${ }^{1,3}$ and producing atrophy of the superior oblique muscle. This was thought to be the aetiology of CSOP for many years but recently it has been losing favour. There are many arguments against this theory. Firstly, birth trauma, even in the event of a forceps delivery, should not cause trochlear nerve damage because trochlear nerve injury usually occurs in deceleration trauma. ${ }^{1}$ Secondly, the majority of cases of CSOP have a tendon abnormality, ${ }^{7,11}$ and the amount of muscle atrophy seen in cases of CSOP cannot be explained by denervation alone. ${ }^{12}$ These factors point to the aetiology of CSOP being developmental and not neurodegenerative. The cause of this structural problem probably lies with a genetic abnormality, which may either occur sporadically or be inherited.
In our report, all the unilateral cases showed muscle sequelae with overaction of the ipsilateral inferior oblique and underaction of the contralateral superior rectus. The diagnosis was supported by a positive BHTT in all cases apart from the father in family $A$ and the mother in family B, in whom the BHTT was equivocal. There are several reasons why the authors believe it is a superior oblique palsy in these two patients as well. The BHTT provides useful information but is not always positive in all cases of superior oblique palsy. ${ }^{13-15}$ Superior oblique paralysis is the most common form of vertical paralytic strabismus, whereas paralysis of the superior rectus is rare and is frequently associated with ptosis of the affected eye. ${ }^{16}$ In the absence of ptosis, early onset of symptoms and so many family members with CSOP, it is likely that the diagnosis in these two cases is CSOP as well.

Franceschetti in 1926 was the first to report a hereditary pattern in CSOP but was unable to give a transmission pattern. ${ }^{6}$ In 1985 and 1986 there were two reports of the hereditary nature of CSOP. The first was by Astle and Rosenbaum, ${ }^{3}$ who looked at three pedigrees and suggested that there may be a multitude of possible genetic transmission patterns. However, this single report is used in Victor McKusick's catalogue of Mendelian inheritance pattern to designate CSOP as an autosomal dominant trait. ${ }^{2}$ The second report, by Harris et al., ${ }^{4}$ described the genetic resemblance of CSOP to Duane's syndrome and suggested that the inheritance, if any, is probably autosomal dominant. It was not until 1996 that another report was presented, with five affected members in one pedigree. There was

Table 2. Orthoptic results for family B

\begin{tabular}{|c|c|c|c|}
\hline & $\begin{array}{l}\text { B II. } 2 \\
\text { mother }\end{array}$ & $\begin{array}{l}\text { B III. } 2 \\
\text { daughter }\end{array}$ & $\begin{array}{l}\text { B III. } 1 \\
\text { daughter }\end{array}$ \\
\hline Age (years)/sex & $43 / \mathrm{F}$ & $7 / F$ & $13 / \mathrm{F}$ \\
\hline Time of onset & Childhood & Childhood & Childhood \\
\hline Visual acuity & $6 / 5 \quad 6 / 5$ & $6 / 5 \quad 6 / 5$ & $6 / 5 \quad 6 / 5$ \\
\hline Abnormal head posture & No & Yes & No \\
\hline Cover test in primary position & $\mathrm{R} / \mathrm{L} 12^{\Delta}$ & $\mathrm{R} / \mathrm{L} 20^{\Delta}$ & Esophoria \\
\hline Binocular single vision & Yes & Yes & Yes \\
\hline Superior oblique underaction & Right & Right & Bilateral \\
\hline Inferior oblique overaction & Right & Right & Bilateral \\
\hline Bielschowsky head tilt test & Equivocal & Positive & Positive \\
\hline
\end{tabular}


A II.3
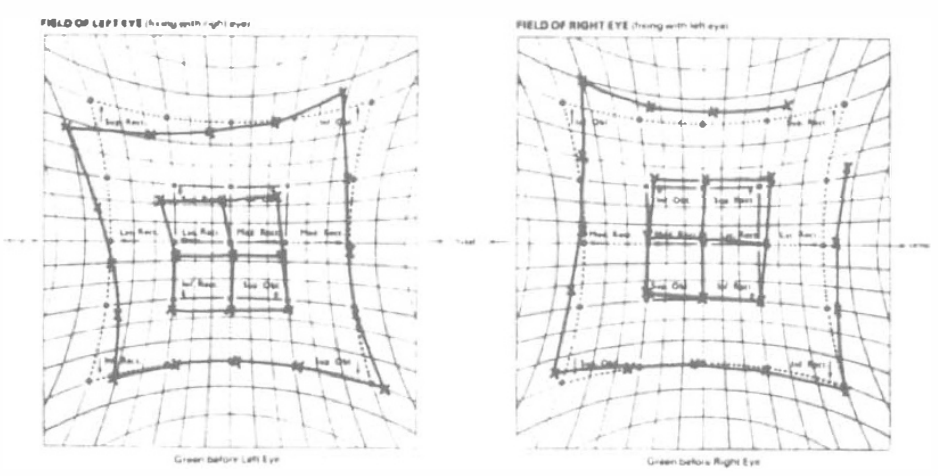

A III. 1
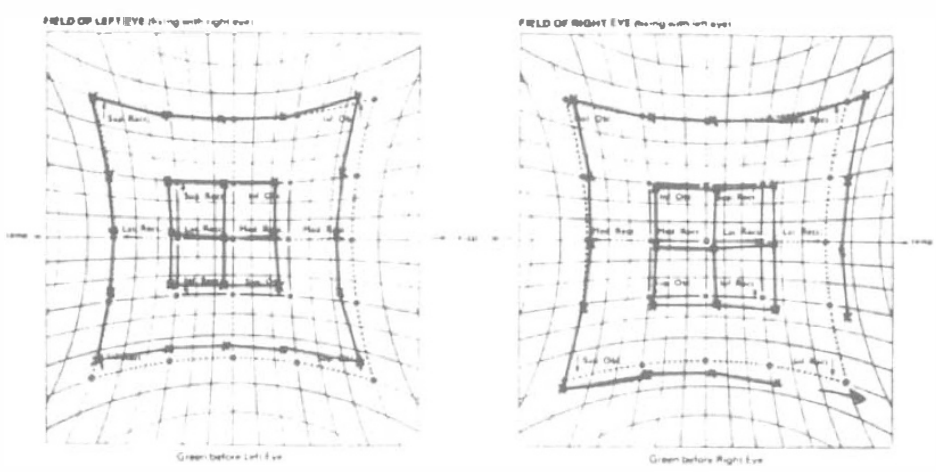

A III. 2
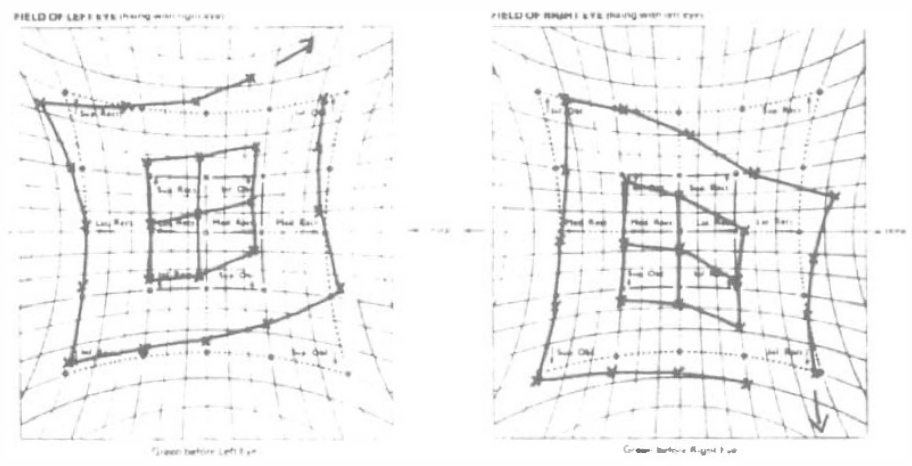

A III. 3
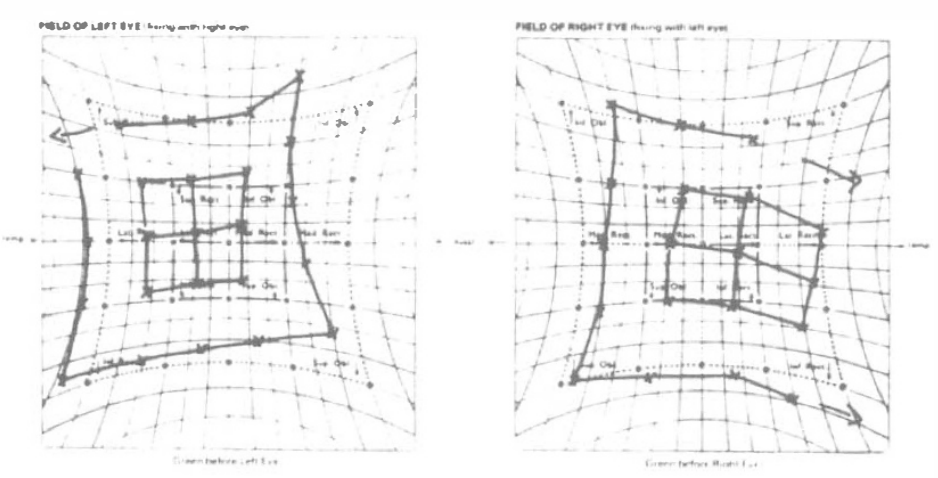

A III. 4
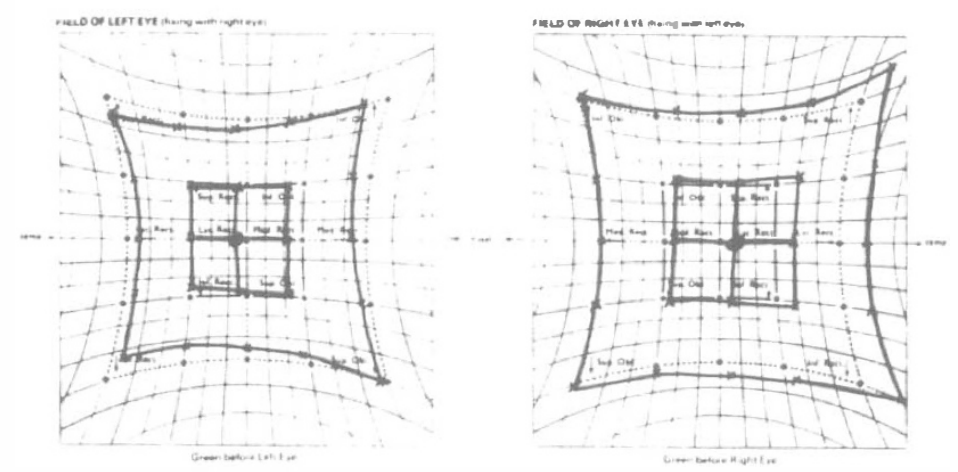

Fig. 1. Hess charts of family A. The father (A II.3) has right superior oblique underaction and the sons (A III.1, A III.2, A III.3) have varying degrees of left superior oblique underaction. The daughter (A III.4) shows a generalized limitation of movement of the left eye. 


\section{A}
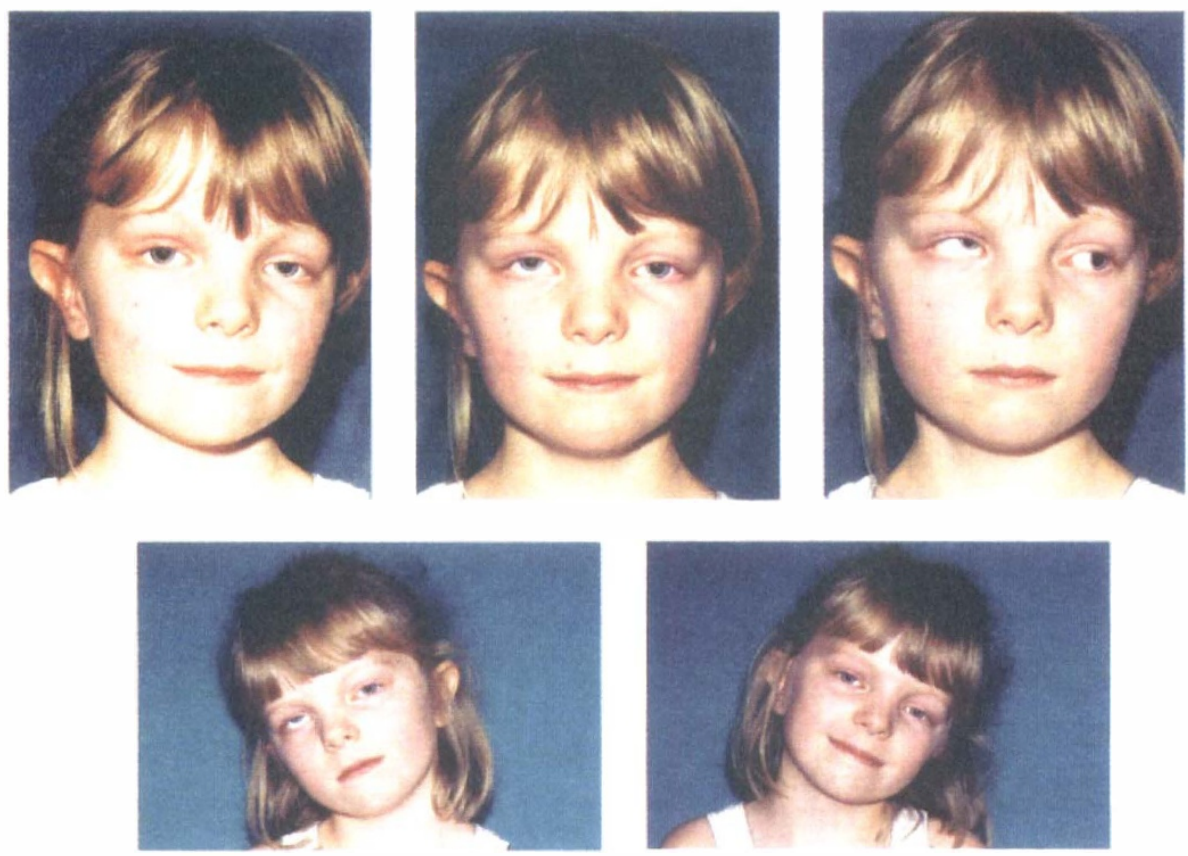

B

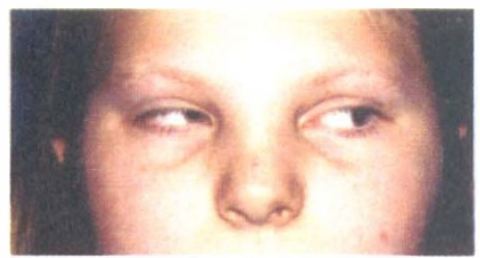

C

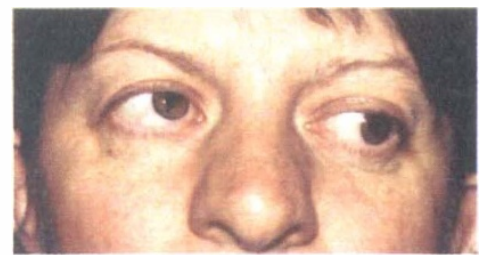

Fig. 2. Family B. (A) Younger daughter (B III.2). Top left: Compensatory head posture. Face turn and head tilt to the left. Top middle: Right hypertropia on straightening the head. Top right: Right hypertropia increases on laevoversion. Middle left and right: Bielschowsky head tilt test showing increased hypertropia with head tilt to the right, and decrease hypertropia with head tilt to the left. (B) Older daughter (B III.1): right hypertropia on laevoversion. (C) Mother (B II.2): right hypertropia on laevoversion.
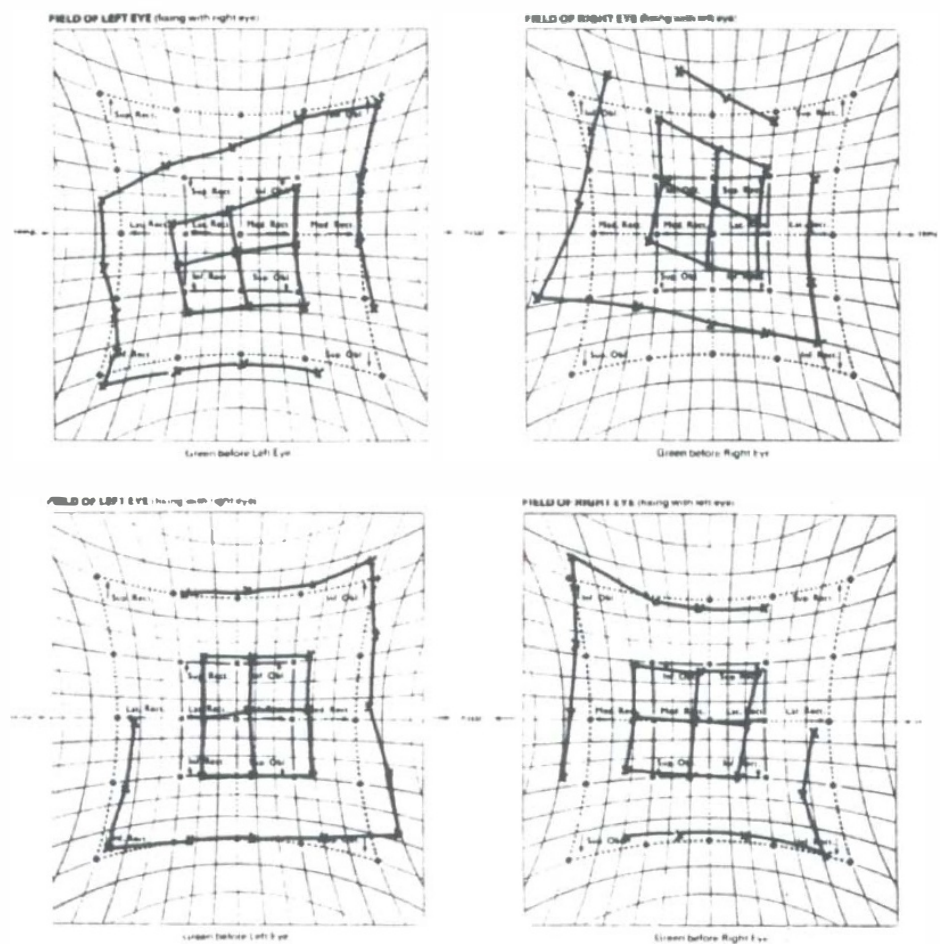

Fig. 3. Family B. Top: Hess charts show the mother (B II.2) with right superior oblique underaction. Bottom: Hess charts show the older daughter (B III.1) with a small degree of bilateral superior oblique underaction. 

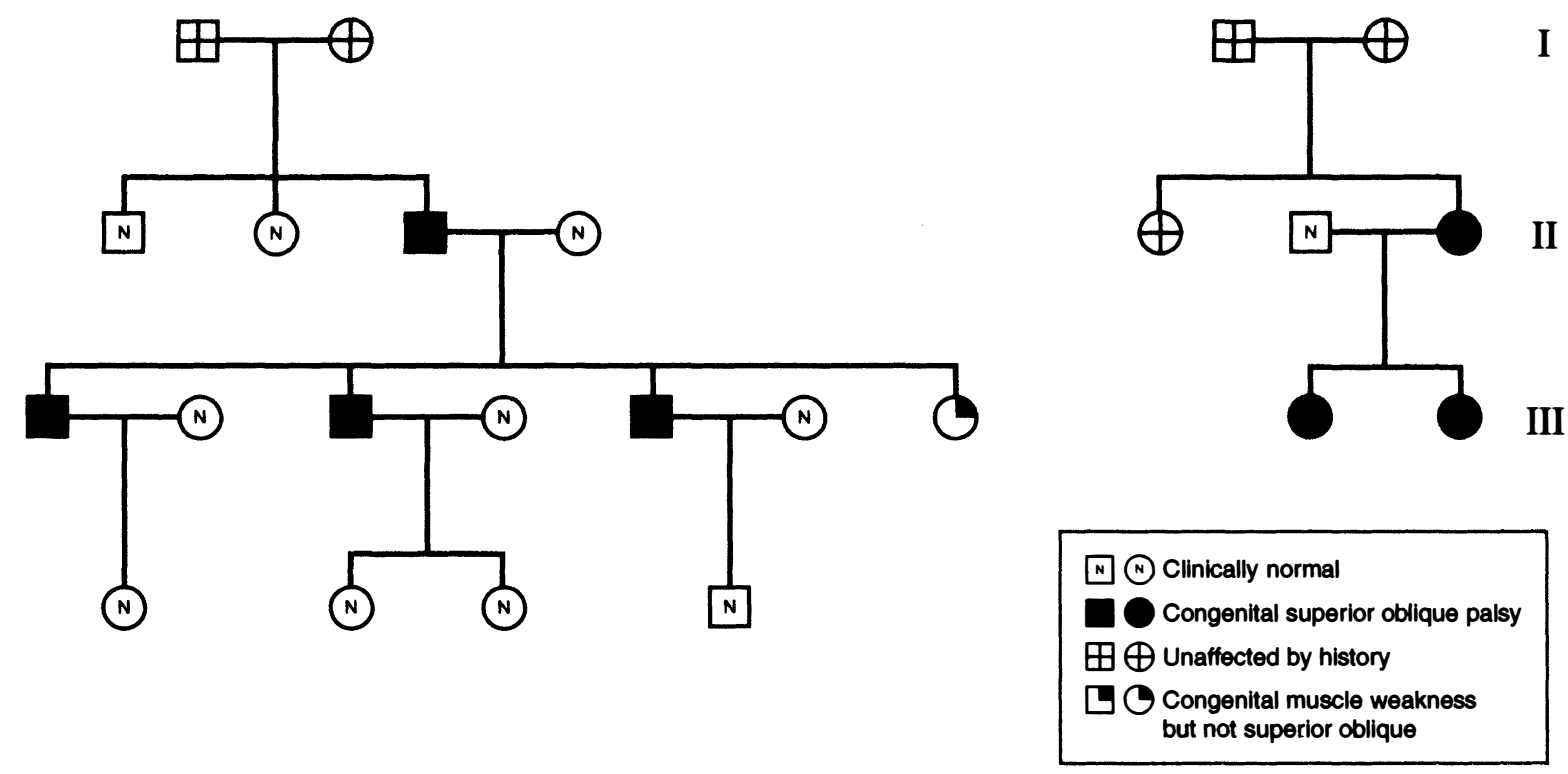

IV

\section{III}

.

Fig. 4. Family trees of families $A$ and $B$.

involvement of three successive generations, including male to male transmission, and the authors concluded that the mode of inheritance is autosomal dominant. ${ }^{5}$

In family A, the daughter's (A III.4) vertical phoria on left gaze which reverses on up- to down-gaze, probably represents weakness of the left superior and inferior rectus muscle, whilst her father and all her brothers most probably have an abnormality of the superior oblique muscle and tendon. It is possible, therefore, that the daughter's problem has developed from the same gene as the sons, and this variation in ocular motility may represent the variable expressivity seen in autosomal dominant disorders. ${ }^{17}$ The signs and symptoms of CSOP range from mild to severe in family $A$ and $B$ and this variable penetrance is well recognised in autosomal dominant disorders. ${ }^{17}$

From the genetic point of view the daughter in family A would be considered as affected, representing a variation of the same genetic problem. Three specific features need to be observed for a trait to be classified as autosomal dominant. The first is that it affects both males and females in equal proportions. All the offspring in both our pedigrees are affected; unfortunately neither pedigree has equal proportions of males and females. The second is that it is transmitted from one generation to the next, which is present in both families, but we expected to find some of the grandchildren in family A affected. The grandchildren range in age from 6 months to 3 years. This may have made subtle cases difficult to detect, or maybe as a result of non-penetrance we have skipping of a generation'. The third is that all forms of transmission between the sexes are observed. Family A exhibits male to male and male to female transmission, and family $B$ exhibits female to female transmission. No other classical pattern of inheritance can be used to explain our family tree. It seems likely that if a genetic pattern exists, it is autosomal dominant.

In family A, one of the sons (A III.1) was asymptomatic and only recognised on screening of the family for the purpose of this study. Harris et al. ${ }^{4}$ had two similar asymptomatic cases in one of their pedigrees, and concluded that many patients may be asymptomatic or misdiagnosed as having an orthopaedic problem. ${ }^{4}$

In conclusion, our families demonstrate what is probably an autosomal dominant form of CSOP, and it is possible that hereditary CSOP is more common than previously reported.

We would like to thank Mr J. Burke and Miss H. Davis for reviewing the manuscript, J. Finch for examination of family B, and Mr K.K.F. Mohammad for all his support.

\section{References}

1. Ellis FD, Helveston EM. Superior oblique palsy: diagnosis and classification. Int Ophthalmol Clin 1976;16:127-35.

2. McKusick VA. Mendelian inheritance pattern in man, 11th ed. Baltimore: Johns Hopkins University Press, 1994:536.

3. Astle WF, Rosenbaum AL. Familial congenital fourth cranial nerve palsy. Arch Ophthalmol 1985;103:532-5.

4. Harris DJ Jr, Memmen JE, Katz NNK, Parks MM. Familial congenital superior oblique palsy. Ophthalmology 1986;93:88-90.

5. Botelho PJ, Giangiacomo JG. Autosomal-dominant inheritance of congenital superior oblique palsy. Ophthalmology 1996;103:1508-11.

6. Franceshetti A. Über doppelseitige, kongenitale (familiare) Trochlearislahmung und ihre Beiziehung zur alternierenden Hyperphorie. Z Augenheilkd 1926;59:27-34.

7. Helveston EM, Krach D, Plager DA, Ellis FD. A new classification of superior oblique palsy based on congenital variations in the tendon. Ophthalmology 1992;99:1609-34.

8. Walsh FB, Hoyt WF. Clinical neuro-ophthalmology, vol 1, 3rd ed. Baltimore: Williams \& Wilkins, 1969:244-6. 
9. Duke-Elder S, Wybar K. Incomitant strabismus. In: DukeElder S, editor. Ocular motility and strabismus. System of Ophthalmology vol 6. London: Henry Kimpton, 1973:711-4.

10. Chan TK, Demer JL. Clinical features of the congental absence of the superior oblique muscle as demonstrated by orbital imaging. J AAPOS 1999;3:143-50.

11. Plager DA. Tendon laxity in superior oblique palsy. Ophthalmology 1992;99:1032-8.

12. Sato M, Yagasaki T, Kora T, Awaya S. Comparison of muscle volume between congenital and acquired superior oblique palsies by magnetic resonance imaging. Jpn J Ophthalmol 1998;42:466-70.

13. Mein J, Trimble R. Ocular deviation. In: Diagnosis and management of ocular motility disorders. 2nd ed. Oxford: Blackwell, 1991:109.
14. Goodier HM. Evaluation of the Bielschowsky's head tilting test. In: Mein J, Moore S, editors. Orthoptics: research and practice. London: Henry Kimpton, 1981:189-97.

15. Doba H, Doba JK, Doba FM, Doba MD, Doba GS. The incidence of atypical adaptation of muscle sequelae following superior oblique palsies. In: Tillson G, editor. Advances in amblyopia and strabismus. VIIth International Orthoptic Congress. Germany: Fahner Verlag, 1991:276-99.

16. von Noorden GK. Paralytic strabismus. In: Klein EA, editor Binocular vision and ocular motility: theory and management of strabismus, 4th ed. St Louis: CV Mosby, 1990:380-7.

17. Mueller RF, Young ID. Patterns of inheritance. In: Parkinson M, editor. Emery's elements of medical genetics, 9th ed. New York: Churchill Livingstone, 1995:78-86. 